\title{
CONTEÚDO DE CARBOIDRATOS EM GEMAS E RAMOS DE MACIEIRA DURANTE O OUTONO E INVERNO EM REGIÃO DE BAIXA OCORRÊNCIA DE FRIO ${ }^{1}$
}

\author{
RUY INACIO NEIVA DE CARVALHO² \& FLÁVIO ZANETTE ${ }^{3}$
}

\begin{abstract}
RESUMO - Objetivou-se quantificar o teor de carboidratos em gemas e ramos de um ano de macieira cv. 'Imperial Gala', com ou sem frio suplementar, durante o outono e inverno, cultivada em região de baixa ocorrência de frio. Os ramos foram coletados em Porto Amazonas-PR, em intervalos de 21 dias, de abril a agosto (19-04, 10-05, 31-05, 21-06, 12-07, 02-08 e 23-08), e receberam ou não tratamento com frio suplementar de 1.440 horas, à temperatura de $4 \mathrm{a} 7^{\circ} \mathrm{C}$. As análises de carboidratos foram realizadas em gemas e porções de ramos adjacentes às mesmas. Os carboidratos solúveis totais foram determinados pelo método do fenol-sulfúrico, realizando-se a leitura por espectrofotometria (absorbância a $490 \mathrm{~nm}$ ). Os carboidratos insolúveis totais foram estimados pelo rendimento da fração de tecido vegetal insolúvel em álcool e solúvel em álcali, após liofilização. Os carboidratos solúveis mais os insolúveis representaram de 13,8 a 20,2 \% da matéria seca de gemas e 9,9 a 15,3\% da matéria seca de ramos de um ano de macieira. Em gemas de macieira, houve maior porcentagem de carboidratos solúveis na entrada em dormência e maior porcentagem de carboidratos insolúveis na dormência mais intensa. A ocorrência de frio precoce antecipou o acúmulo de carboidratos insolúveis nas gemas enquanto o frio, durante a endodormência, promoveu o acúmulo de carboidratos solúveis. Houve aumento do conteúdo de carboidratos solúveis em ramos com o desenvolvimento da endodormência enquanto as variações do conteúdo de carboidratos insolúveis não foram significativas.
\end{abstract}

Termos para Indexação: Malus domestica Borkh., 'Imperial Gala', fisiologia, dormência.

\section{CARBOHYDRATE CONTENT IN BUDS AND STEMS OF APPLE TREES DURING AUTUMN AND WINTER IN A REGION OF LOW CHILL OCCURENCE}

\begin{abstract}
This work aimed at evaluating the carbohydrate content of one year old buds and stems of apple trees cv. 'Imperial Gala' with or without supplementary chill during autumn and winter, cultivated in a region of low chill occurence. The stems were collected in Porto Amazonas, Parana State, Brazil, at intervals of 21 days from April to August (04/19, 05/10, 05/31, 06/21, 07/12, 08/02 and 08/23) and were treated or not with 1,440 hours of chill $\left(4\right.$ to $7^{\circ} \mathrm{C}$ ). The carbohydrates were analysed in buds and stem tissues close to the buds. The soluble carbohydrates (SC) were evaluated by the phenol-sulfuric acid method and the final determination was made by spectrophotometry ( $490 \mathrm{~nm}$ absorbance). The non-soluble carbohydrates (NC) were estimated by the mass of vegetal tissues non-soluble in alcohol and soluble in alcaline medium, after freeze drying. The total carbohydrate (SC $+\mathrm{NC}$ ) content represented 13.8 to $20.2 \mathrm{~g} .100 \mathrm{gg}^{-1}$ of dry matter of buds and 9.9 to $15.3 \mathrm{~g} .100 \mathrm{~g}^{-1}$ of dry matter of stems. The buds presented a higher level of SC in the initial dormancy period and a higher level of $\mathrm{NC}$ in the more intense dormancy period. The NC accumulation in buds were anticipated by the early chill treatment and the chill treatment during endodormancy promoted the SC accumulation. The SC content in stems increased along the dormancy development while the NC content remained constant.
\end{abstract}

Index Terms: Malus domestica Borkh., 'Imperial Gala', physiology, dormancy.

\section{INTRODUÇÃO}

Durante as estações desfavoráveis, as plantas limitam ou cessam seu crescimento de forma a permitir a sobrevivência em períodos de escassez de água ou de baixas temperaturas, caracterizando o período de dormência. Nessa fase, as atividades metabólicas essenciais continuam a ocorrer, embora com intensidade reduzida (Petri et al., 1996).

Segundo Lang et al. (1987), a endodormência ocorre nos meses mais frios em que o não-desenvolvimento da gema é resultante de uma série de eventos bioquímicos e fisiológicos que acontecem em tecidos meristemáticos ou regiões muito próximas.

A baixa temperatura é um fator ambiental de grande influência na endodormência de gemas (Crabbé \& Barnola, 1996), em especial, de macieira (Pereira et al., 2001; Zanette et al., 2000). Os processos fisiológicos internos envolvidos na entrada e saída da endodormência podem estar relacionados com diversos fatores, dentre os quais o fluxo de carboidratos e a translocação de reservas a curta distância (Marquat et al., 1999).

Em rosáceas, a maior parte do carbono fixado na fotossíntese é armazenado na forma de amido no cloroplasto ou é transferido ao citossol e convertido nos carboidratos solúveis sacarose e sorbitol (Quick \& Schaffer, 1996). Apenas traços de outros carboidratos são encontrados, como a rafinose, a estaquiose e o mioinositol (Salisbury \& Ross, 1992). Desde a década de 1960, o sorbitol tem sido determinado como o principal assimilado translocado na macieira (Williams et al., 1967) e, mais recentemente, em outras rosáceas, como a pereira (Herter et al., 2001) e o pessegueiro (Marquat et al., 1999).

No pessegueiro, os carboidratos totais armazenam-se em ramos, atingindo um máximo na metade do período de repouso (Flore \& Layne, 1996). Em cerejeiras, os carboidratos não-estruturais (glucose, frutose, sacarose, rafinose, sorbitol e amido) estão em maior concentração em tecidos perenes durante a abscisão foliar e decrescem até pouco antes da brotação (Keller \& Loescher, 1989).

Objetivou-se quantificar o conteúdo de carboidratos em gemas e ramos de um ano de idade de macieira cv. 'Imperial Gala', com ou sem frio suplementar, durante o outono e inverno, cultivadas em região de baixa ocorrência de frio.

\section{MATERIALEMÉTODOS}

O trabalho foi realizado com ramos de macieira da cultivar 'Imperial Gala' coletados no período de abril a agosto de 2000, em pomar com 5 anos de idade, conduzido em plantio adensado (4,0 x 1,35 m), na Fazenda Agropecuária Boutin, em Porto Amazonas - PR (25,55 latitude Sul, 49,90 de longitude Oeste e $795 \mathrm{~m}$ de altitude). A quantificação do frio ocorrido na região foi determinada segundo o método do número de horas de frio (HF) abaixo de $7,2^{\circ} \mathrm{C}$ e pelo método da conversão de temperaturas para unidades de frio (UF), baseado no modelo Carolina do Norte, citados por Petri et al. (1996).

Os ramos com comprimento superior a $30 \mathrm{~cm}$ e com inserção e disposição espacial oblíqua foram coletados em sete datas distintas: 19-

\footnotetext{
${ }^{1}$ (Trabalho 142/2003). Recebido: 15/09/2003. Aceito para publicação: 21/07/2004. Parte da tese do primeiro autor apresentada à Universidade Federal do Paraná para obtenção do título de Doutor em Ciências.

${ }^{2}$ Engenheiro Agrônomo, Dr., Professor Adjunto II do Centro de Ciências Agrárias e Ambientais da Pontifícia Universidade Católica do Paraná. Rodovia BR 376, Km 14, CEP 83010-500 - São José dos Pinhais - PR. Fone: (41) 382-1454. ruy@rla01.pucpr.br

${ }^{3}$ Eng. Agrônomo, Dr., Professor de Fruticultura do Departamento de Fitotecnia e Fitossanitarismo da Universidade Federal do Paraná. Rua dos Funcionários, 1540, CEP 80035-050. Curitiba-Paraná. Fone: (41) 350-5650. flazan@ufpr.br
} 
04, 10-05, 31-05, 21-06, 12-07, 02-08 e 23-08. Após cada coleta, os ramos receberam ou não tratamento com frio suplementar de 1.440 horas, à temperatura de 4 a $7^{\circ} \mathrm{C}$ em geladeira.

As análises de carboidratos foram realizadas em gemas e porções de ramos adjacentes às mesmas. A coleta das gemas foi feita cortando-se as mesmas e retirando-se as cinco escamas externas, e dos ramos pelo seu fracionamento em porções com $1 \mathrm{~cm}$ de comprimento e divididas ao meio por um corte longitudinal, mantendo-se para análise a metade que possuía uma gema já eliminada. As determinações foram realizadas no Laboratório de Carboidratos de Exsudatos Vegetais do Departamento de Bioquímica e no Laboratório de Cromatografia e Espectrofotometria do Departamento de Química da Universidade Federal do Paraná.

Os carboidratos solúveis totais foram determinados pelo método do fenol-sulfúrico (Dubois et al., 1956). A extração etanólica foi realizada, tratando-se $100 \mathrm{mg}$ de amostra com $30 \mathrm{~mL}$ de etanol $80 \%$ por $30 \mathrm{~min}$ a $100^{\circ} \mathrm{C}$, em banho-maria. Foram utilizadas alíquotas de $50 \mu \mathrm{L}$ das frações solúveis em etanol, nas quais foram adicionados $450 \mu \mathrm{L}$ de água destilada e, posteriormente, $0,5 \mathrm{~mL}$ de fenol e $2,5 \mathrm{~mL}$ de ácido sulfúrico concentrado. A leitura foi realizada em espectrofotômetro por absorbância $490 \mathrm{~nm}$. Calculou-se o conteúdo de carboidratos solúveis totais em $\mathrm{mg}^{-\mathrm{g}^{-1}} \mathrm{de}$ matéria seca de material vegetal.

Para a determinação dos carboidratos insolúveis totais, uma amostra de $20 \mathrm{mg}$ da fração insolúvel em etanol liofilizada foi tratada com hidróxido de sódio $0,02 \mathrm{~N}$ em tubo de ensaio, por 30 minutos, a $90^{\circ} \mathrm{C}$ (Marquat et al., 1999). A fração solúvel em álcali foi liofilizada, pesada e o rendimento em compostos insolúveis em álcool foi calculado em $\mathrm{mg} . \mathrm{g}$ ${ }^{1}$ de matéria seca de material vegetal.

A análise estatística para as gemas e porções de ramos foi realizada separadamente, resultando em dois experimentos. O delineamento experimental adotado nos dois casos foi o de parcelas subdivididas no tempo com o fator principal arranjado em blocos casualizados, com três repetições. A parcela principal foi o tratamento ou não com frio suplementar, e a subparcela foram as sete datas de coleta, totalizando 14 tratamentos. A comparação entre médias de tratamentos foi feita pelo teste de Tukey, ao nível de significância de $5 \%$.

\section{RESULTADOS E DISCUSSÃO}

A quantidade de frio ocorrida na região até agosto foi de 386 horas de frio abaixo de $7,2^{\circ} \mathrm{C}$ ou 211,5 unidades de frio, porém até julho, apenas 95 horas ou - 86,0 unidades de frio haviam sido acumuladas. Embora ainda não tenha sido definido o requerimento em frio para a macieira da cultivar estudada, segundo Petri et al. (1996), a macieira da cultivar 'Gala', que originou a cultivar 'Imperial Gala', requer 600 horas de frio abaixo de $7,2^{\circ} \mathrm{C}$ para a quebra da dormência, quantidade de frio muito além da ocorrida no pomar de macieiras estudado.

Os carboidratos solúveis mais os insolúveis representaram de 13,8 a 20,2 \% da matéria seca de gemas de um ano de macieira (Tabela 1), sendo constituintes essenciais cujas variações podem ser causa ou consequiência da dormência. Os carboidratos solúveis (sacarose, glucose, frutose, sorbitol e outros) têm importância na regulação osmótica e transporte, enquanto os carboidratos insolúveis, especialmente o amido, são importantes formas de reserva.

A maior porcentagem de carboidratos solúveis em relação aos insolúveis na entrada em dormência sugere maior predisposição ao transporte pela gema, enquanto a situação inversa na dormência mais intensa sugere a predisposição ao armazenamento para uso futuro. A movimentação passiva de carboidratos solúveis pode ocorrer a pequenas distâncias por meio da difusão simples ou difusão facilitada por proteínas transportadoras da membrana (Buckhout \& Tube, 1996; Raven et al., 2001). Para as gemas não tratadas com frio suplementar, na dormência mais profunda (12-07), o conteúdo em carboidratos solúveis foi 41,2\% menor que o conteúdo na entrada em dormência em 19-04, enquanto a situação é inversa para os carboidratos insolúveis cujo conteúdo foi 19,1\% maior que em 19-04 (Tabela 1).

No período de abril a maio, as gemas que não receberam frio suplementar, apresentaram acentuada redução do conteúdo de carboidratos solúveis e pequena redução de carboidratos insolúveis. Possivelmente, a degradação do amido pode estar relacionada com o fornecimento de glucose aos tecidos para a manutenção de um gradiente de concentração para proteção em períodos de frio excessivo, pois o amido possui um efeito osmótico desprezível (Preiss \& Sivak, 1996). A partir de 31-05, o conteúdo de carboidratos solúveis apresentou uma pequena redução, enquanto o conteúdo de carboidratos insolúveis apresentou uma elevação (Tabela 1).

TABELA 1 - Conteúdo de carboidratos solúveis e insolúveis nas gemas de macieira da cultivar 'Imperial Gala' que não receberam frio suplementar no período de abril a agosto de 2000.

\begin{tabular}{cccc}
\hline Datas & $\begin{array}{c}\text { Carboidratos } \\
\text { solúveis } \\
(\%)\end{array}$ & $\begin{array}{c}\text { Carboidratos } \\
\text { insolúveis } \\
(\%)\end{array}$ & $\begin{array}{c}\text { Total de } \\
\text { carboidratos } \\
(\%)\end{array}$ \\
\hline $19-04$ & $10,8 \mathrm{a}^{*}$ & $9,4 \mathrm{ab} *$ & 20,2 \\
$10-05$ & $6,8 \mathrm{bc}$ & $8,4 \mathrm{ab}$ & 15,2 \\
$31-05$ & $6,6 \mathrm{bc}$ & $7,2 \mathrm{~b}$ & 13,8 \\
$21-06$ & $7,3 \mathrm{~b}$ & $10,7 \mathrm{ab}$ & 18,0 \\
$12-07$ & $6,3 \mathrm{c}$ & $11,2 \mathrm{ab}$ & 17,5 \\
$02-08$ & $5,4 \mathrm{~d}$ & $12,5 \mathrm{a}$ & 17,9 \\
$23-08$ & $6,1 \mathrm{~cd}$ & $11,6 \mathrm{a}$ & 17,7 \\
\hline
\end{tabular}

*Médias seguidas por letras distintas nas colunas diferem entre si, pelo Teste de Tukey, ao nível de significância de 5\%.

O tratamento com frio, no mês de abril e início de maio, não alterou a dinâmica de redução do nível de carboidratos solúveis, porém, nos outros meses, favoreceu o acúmulo nas gemas. As variações dos conteúdos de carboidratos insolúveis em gemas que receberam frio suplementar, não foram significativas em todo o período estudado (Tabela 2). A redução de carboidratos insolúveis que ocorreu nas gemas sem frio suplementar no início da endodormência, não aconteceu quando o frio foi aplicado, sugerindo que este metabolismo de hidrólise do amido pode estar relacionado à redução gradual de temperatura de outono e não ao frio intenso e constante. Os resultados indicam que a ocorrência de frio precoce antecipa o acúmulo de carboidratos de reserva enquanto o frio, durante a endodormência, promove o acúmulo de carboidratos de transporte. Os carboidratos solúveis acumulados nas gemas poderiam ser provenientes dos ramos adjacentes às gemas, uma vez que os carboidratos insolúveis nas gemas, possíveis fontes de carboidratos solúveis, mantiveram níveis constantes quando foi fornecido frio suplementar. $\mathrm{O}$ amido poderia sofrer hidrólise produzindo glicose que, por sua vez, poderia formar sorbitol, importante açúcar álcool de transporte nas plantas da família Rosaceae (Loescher \& Everard, 1996; Quick \& Schaffer, 1996; Williams et al., 1967).

A baixa temperatura pode inibir o transporte de açúcares na planta, porém, mesmo sob a manutenção do frio, pode ocorrer a retomada do fluxo cuja dinâmica está em função da magnitude ou da taxa de resfriamento (Thorpe \& Minchin, 1996). Estes fatos sugerem que, mesmo no outono e

TABELA 2 - Conteúdo de carboidratos solúveis e insolúveis nas gemas de macieira da cultivar 'Imperial Gala' que receberam 1.440 horas de frio suplementar no período de abril a agosto de 2000.

\begin{tabular}{cccc}
\hline Datas & $\begin{array}{c}\text { Carboidratos } \\
\text { solúveis } \\
(\%)\end{array}$ & $\begin{array}{c}\text { Carboidratos } \\
\text { insolúveis } \\
(\%)\end{array}$ & $\begin{array}{c}\text { Total de } \\
\text { carboidratos } \\
(\%)\end{array}$ \\
\hline $19-04$ & $11,0 \mathrm{a}^{*}$ & $9,9^{\text {ns }}$ & 20,9 \\
$10-05$ & $6,4 \mathrm{~d}$ & 13,7 & 20,1 \\
$31-05$ & $7,4 \mathrm{c}$ & 12,2 & 19,6 \\
$21-06$ & $9,5 \mathrm{~b}$ & 11,1 & 20,6 \\
$12-07$ & $10,0 \mathrm{~b}$ & 9,4 & 19,4 \\
$02-08$ & $7,8 \mathrm{c}$ & 12,8 & 20,6 \\
$23-08$ & $7,1 \mathrm{~cd}$ & 12,7 & 19,8 \\
\hline
\end{tabular}

ns - Diferenças não significativas.

*Médias seguidas por letras distintas na coluna diferem entre si, pelo teste de Tukey, ao nível de significância de 5\%. 
no inverno, o transporte de carboidratos a curta distância pode ocorrer, caracterizando-se por um dos eventos fisiológicos que regulam a capacidade de desenvolvimento das gemas (Lang et al., 1987; Marquat et al., 1999). A movimentação passiva de carboidratos (Raven et al., 2001), mesmo em período de reduzida atividade metabólica (Petri et al., 1996), predispõe reservas para o início de um novo ciclo de crescimento, seja para formação de ramos mistos estruturais seja para ramos especializados em frutificação (dardos e esporões). A brotação uniforme e vigorosa de gemas floríferas e vegetativas, em virtude da disponibilidade de reservas, é componente de influência direta para a formação dos frutos.

O conteúdo de carboidratos solúveis mais os insolúveis, nos ramos de um ano, encontraram-se na faixa de 9,9 a $15,3 \%$, indicando que são componentes essenciais durante o período de dormência da planta (Tabela 3). Mesmo na entrada em dormência, o conteúdo de carboidratos solúveis foi menor que o de carboidratos insolúveis, em decorrência da maior lignificação dos tecidos dos ramos, com maior quantidade de celulose.

TABELA 3 - Conteúdo de carboidratos solúveis e insolúveis nos ramos de macieira da cultivar 'Imperial Gala' que não receberam frio suplementar no período de abril a agosto de 2000.

\begin{tabular}{lccc}
\hline Datas & $\begin{array}{c}\text { Carboidratos } \\
\text { solúveis } \\
(\%)\end{array}$ & $\begin{array}{c}\text { Carboidratos } \\
\text { insolúveis } \\
(\%)\end{array}$ & $\begin{array}{c}\text { Total de } \\
\text { carboidratos } \\
(\%)\end{array}$ \\
\hline $19-04$ & 3,6 bc* & $9,8^{\text {ns }}$ & 13,4 \\
$10-05$ & $2,3 \mathrm{~d}$ & 7,6 & 9,9 \\
$31-05$ & $3,0 \mathrm{~cd}$ & 9,5 & 12,5 \\
$21-06$ & $3,0 \mathrm{~cd}$ & 8,7 & 11,7 \\
$12-07$ & $4,4 \mathrm{~b}$ & 8,9 & 13,3 \\
$02-08$ & $5,6 \mathrm{a}$ & 9,7 & 15,3 \\
$23-08$ & $3,8 \mathrm{~b}$ & 8,1 & 11,9 \\
\hline
\end{tabular}

ns - Diferenças não significativas.

*Médias seguidas por letras distintas na coluna diferem entre si, pelo teste de Tukey, ao nível de significância de 5\%.

Com a entrada no período de dormência, a redução do conteúdo de carboidratos solúveis ocorrida nas gemas também ocorreu nos ramos, indicando que, nesta etapa, há também transporte de carboidratos para regiões do ramo mais distantes das gemas ou utilização na respiração dos tecidos. A partir de maio, com o desenvolvimento da endodormência, o conteúdo de carboidratos solúveis aumentou, possivelmente devido ao acúmulo dos carboidratos solúveis provenientes das gemas. As variações do conteúdo de carboidratos insolúveis nos ramos não foram significativas, talvez pela elevada concentração de outros carboidratos insolúveis (celulose), que faz com que pequenas variações no conteúdo de amido não possam ser observadas (Tabela 4).

TABELA 4 - Conteúdo de carboidratos solúveis e insolúveis nos ramos de macieira da cultivar 'Imperial Gala' que receberam 1.440 horas de frio suplementar no período de abril a agosto de 2000.

\begin{tabular}{cccc}
\hline Datas & $\begin{array}{c}\text { Carboidratos } \\
\text { solúveis } \\
(\%)\end{array}$ & $\begin{array}{c}\text { Carboidratos } \\
\text { insolúveis } \\
(\%)\end{array}$ & $\begin{array}{c}\text { Total de } \\
\text { carboidratos } \\
(\%)\end{array}$ \\
\hline $19-04$ & $4,3 \mathrm{~b}^{*}$ & $6,2^{\mathrm{ns}}$ & 10,5 \\
$10-05$ & $5,0 \mathrm{ab}$ & 7,9 & 12,9 \\
$31-05$ & $4,4 \mathrm{~b}$ & 7,4 & 11,8 \\
$21-06$ & $4,9 \mathrm{ab}$ & 7,3 & 12,2 \\
$12-07$ & $4,8 \mathrm{ab}$ & 6,7 & 11,5 \\
$02-08$ & $5,3 \mathrm{a}$ & 8,9 & 14,2 \\
$23-08$ & $4,6 \mathrm{ab}$ & 8,7 & 13,3 \\
\hline
\end{tabular}

ns - Diferenças não significativas.

*Médias seguidas por letras distintas na coluna diferem entre si, pelo teste de Tukey, ao nível de significância de 5\%.

\section{CONCLUSÃO}

1. Os carboidratos solúveis mais os insolúveis representaram de 13,8 a 20,2 \% da matéria seca de gemas e 9,9 a 15,3\% da matéria seca de ramos de um ano de macieira.

2. Em gemas de macieira, houve maior porcentagem de carboidratos solúveis na entrada em dormência e maior porcentagem de carboidratos insolúveis na dormência mais intensa.

3. A ocorrência de frio precoce antecipou o acúmulo de carboidratos insolúveis nas gemas, enquanto o frio, durante a endodormência, promoveu o acúmulo de carboidratos solúveis.

4. Houve aumento do conteúdo de carboidratos solúveis em ramos com o desenvolvimento da endodormência, enquanto as variações do conteúdo de carboidratos insolúveis não foram significativas.

\section{REFERÊNCIAS BIBLIOGRÁFICAS}

BUCKHOUT, T. J.; TUBBE, A. Structure, mechanisms of catalysis, and regulation of sugar transporters in plants. In: ZAMSKI, E.; SCHAFFER, A. A. Photoassimilate distribution in plants and crops: source-sink relationships. New York: Marcel Dekker, 1996. p.229-260.

CRABBÉ, J.; BARNOLA, P. A. New Conceptual Approach to Bud Dormancy in Woody Plants. In: LANG,G.A. (Ed.) Plant Dormancy: physiology, biochemistry and molecular biology. New York: CAB International, 1996. p.83-113.

DUBOIS, M.; GILLES, K. A.; HAMILTON, J. K.; REBERS, P. A.; SMITH, F. Colorimetric method for determination of sugars and related substances. Analytical Chemistry, Washington, v.28, n.3, p.350356,1956

FLORE, J. A.; LAYNE, D. R. Prunus. In: ZAMSKI, E.; SCHAFFER, A. A. Photoassimilate distribution in plants and crops: source-sink relationships. New York: Marcel Dekker, 1996. p.825-849.

HERTER, F. G.; GARDIN, J. P. P.; BACARIN, M.; TREVISAN, R.; VERÍSSIMO, V. Níveis de carboidratos em tecidos de pereira cv. Nijisseiki em duas épocas que antecedem o florescimento. In: CONGRESSO BRASILEIRO DE FISIOLOGIA VEGETAL, 8., 2001, Ilhéus. Anais... CD-ROM.

KELLER, J. D.; LOESCHER, W. H. Nonstructural carbohydrate partitioning in perennial parts of sweet cherry. Journal of the American Society for Horticultural Science, Alexandria, v.114, p.969-975, 1989.

LANG, G. A.; EARLY, J. D.; MARTIN, G. C.; DARNELL, R. L. Endo-, para- and ecodormancy: physiological terminology and classification for dormancy research. Hortscience, Alexandria, v.22, p.371-178, 1987.

LOESCHER, W. H.; EVERARD, J. D. Sugar alcohol metabolism in sinks and sources. In: ZAMSKI, E.; SCHAFFER, A. A. Photoassimilate distribution in plants and crops: source-sink relationships. New York: Marcel Dekker, 1996. p.185-207.

MARQUAT, C.; VANDAMME, M.; GENDRAUD, M.; PÉTEL,G. Dormancy in vegetative buds of peach: relation between carbohydrate absorption potentials and carbohydrate concentration in the bud during dormancy and its release. Scientia Horticulturae, Amsterdam, v.79, p.151-162, 1999.

PEREIRA, J. E. S.; FORTES, G. R. L.; SILVA, J. B. Efeito da aplicação de baixa temperatura em plantas de macieira sobre o crescimento durante a aclimatização. Pesquisa Agropecuária Brasileira, Brasília, v.36, n.1, p.89-95, 2001

PETRI, J. L.; PALLADINI, L. A.; SCHUCK, E.; DUCROQUET, J. P.; MATOS, C. S.; POLA, A. C. Dormência e indução da brotação de fruteiras de clima temperado. Florianópolis: EPAGRI, 1996. 110p. (Boletim Técnico, 75).

PREISS, J.; SIVAK, M. N. Starch synthesis in sink and sources. In: ZAMSKI, E.; SCHAFFER, A. A. Photoassimilate distribution in plants and crops: source-sink relationships. New York: Marcel Dekker, 1996. p.63-96.

QUICK, W. P.; SCHAFFER, A. A. Sucrose metabolism in sources and sinks. In: ZAMSKI, E.; SCHAFFER, A. A. Photoassimilate distribution in plants and crops: source-sink relationships. New 
York: Marcel Dekker, 1996. p.115-156

RAVEN, P. H.; EVERT, R. F.; EICHHORN, S. E. Biologia vegetal. Rio de Janeiro: Ed. Guanabara Koogan, 2001. 906 p.

SALISBURY, F. B.; ROSS C. W. Plant physiology. Califórnia: Wadsworth Publishing Company, 1992. 682p.

THORPE, M. R.; MINCHIN, P. E. H. Mechanisms of long- and shortdistance transport from sources to sinks. In: ZAMSKI, E.; SCHAFFER, A. A. Photoassimilate distribution in plants and crops: source-sink relationships. New York: Marcel Dekker, Inc, 1996. p.261-282.
WILLIAMS, M. W.; MARTIN, G. C.; STAHLY, E. A. The movement and fate of sorbitol- ${ }^{14} \mathrm{C}$ in the apple tree and fruit. Proceedings of the American Society for Horticultural Science, Geneva, v.90, p.2024, 1967.

ZANETTE, F.; CARVALHO, R. I. N.; DRON, C. Effect of low temperature on dormancy intensity in one, two and three year-old-buds of apple tree. Short Communications of Second International Symposium on Plant Dormancy, Angers, p.13-17, 2000. 